\title{
Textural Research on Modeling Characteristics of Totem-Dragonin Qiandongnan Miao's Ideology
}

\author{
Zhu Cheng', Qiong Liu ${ }^{2}$, Xuemin Cheng ${ }^{2, *}$ \\ ${ }^{1}$ National folk culture and art research center of Hunan province, Huaihua University, Huaihua Hunan, \\ 418008, China \\ ${ }^{2}$ The department of artistic design of Huaihua University, Huaihua Hunan, 418008, China \\ *Corresponding author
}

Keywords: Dragon, Modeling characteristic, Textural research, Miao.

\begin{abstract}
Totem of dragon condenses and gathers the psychological reflection of a number of "dragons" in Qiandongnan Miao's traditional cultural ideology. The model is ancient, simple, naïve and lively. Regarding the chaotic characteristic of primitive thinking mode, it expresses the unique creative consciousness and context, and shows the Miao people's aesthetic taste of being brutal and earthy. The study on the arctic technique of "dragon" with inheritance, regionalism and mutual infiltration plays an important role in preserving and carrying forward the excellent culture of Miao nationality.
\end{abstract}

\section{Introduction}

In the initial ideology, the totem injected human "dream thinking". Human associated them with animals and plants through fantastic transformation in dreams and then blood relationship happened. ${ }^{1}$ With the evolution of totem culture, totem was given the idea that "ancestors stemmed from the totem" and had the humanistic connotation of "relative", such as "dog" totem of Yao nationality, "butterfly" totem of Miao nationality and "dragon and phoenix" totem in the history of China. Mutual transformation idea of human and totem has a deep root. The extended meanings "blood relationship" and "relative" were not just infused into the totem . besides, it became the social cultural implication of nature worship, god worship and ancestor worship and was carved in human life, production, folk customs, religious faith and social idea, etc. Besides, the totem existed in various human social activities (material appeal and spiritual activity) so that it finally became a national and popular art image which was popularized in national art and literary works. The totem has the image and features of universality, individuality and versatility due to origin differences.

"Dragon" is a traditional propitious totem in Chinese nation, with the symbolic meanings of "power, dignity and honor". It is also the mark of "luckiness and success". It is used as god worship. "Dragon" became the symbol of Huaxia Nationality and Huaxia culture. "Dragon" totem is a kind of symbol, connotation and blood relationship for Chinese descendants. However, the Miao nationality in the southeast of Guizhou Province holds worship mentality, compatibility and universality mentality for "Dragon" totem. Besides, their national peculiarity mentality is especially obvious.

Belief, legend, living environment and aesthetic standard reflect material appeal and spiritual pursuit of a nation, and show culture and art implication of a nation. From the perspective of extensive meaning of totemism, totemism once existed for a long time. It was an art form which occupied a dominant position in ancient society and had far-reaching influence on the specific historical period as well as regional economy, culture and art in the specific history. The toteom existed in material carriers such as drawing, sculpture, dance and architecture. To seek the trace of dragon totem worship of Miao nationality, we investigated Miao embroidery artists, silver masters, paper horse maters, and carvers in the southeast of Guizhou Province and found that "dragon" psychological response existed in traditional culture subconscious of Miao nationality, folk customs, totemism and religious activities. Especially in the ideology of Miao nationality in Shidong, Taijiang County, Guizhou, the idea of dragon totem still penetrates imagination and original thunking feature. 
Meanwhile, multiple kinds of totems gather in the Miao nationality in the southeast of Guizhou Province, such as cow totem, butterfly totem and brambling totem, but these tomes basically have corresponding unified modeling mode and relatively stable morphological characteristics in terms of morphological description and image confirmation. Only dragon totem has mysterious color in this region in terms of "form" and "modeling". This mainly originated from a special culture phenomenon in the Miao nationality. Dragon image must be passed on from mouth to mouth and taught face to face by folk artisans to a large extent. Thus, dragon totem is based on traditional features and aesthetic idea in terms of fundamental form treatment. Due to the restrictions of folk customs, spiritual appeal, craftsmen's creation talent and aesthetic habits, dragon totems in each place show numerous types and forms.

\section{Dream and obscurantism of modeling}

The Miao nationality lives in the top of mountain. For the historical reason, the Miao nationality in the southeast of Guizhou Province lives in mountains. The dangerous and lifeful living environment promotes hard-bitten will of Miao nationality, and romantic and life attitude full of pursuits, and gives them wisdom. Thus, they own the art expression form with dream and obscurantism - dragon totem modeling.

Dream and obscurantism were the most plain language confession of ancient people for nature and life, ethnic group and proliferation as well as social and fashion. Harmony, beauty, weirdness, origin and national interest make dragon totem art of Miao nationality full of "Wuximan"-type creation enthusiasm, innocence and humor, and interpret the plain psychological longing and vision of Miao nationality. Folk artists of Miao nationality apply the methods similar to artists' methods, their life experience and perception of dragon totem, their findings and ideas in life and whacky thinking modes to create multi-idea and multi-thinking dragon totem art form. Such misted and miraculous form shows aesthetic psychology, aesthetic emotion and aesthetic joy of Miao people and conveys dream feature and intention.

(1)Totemism. The totem is not the art in essential sense, but it is the soil of art. Thus, totem culture contains the art describing everything in the world and art creation enthusiasm. It is exactly such utilization sign of totem art that facilitates the phenomenon of numerous gods integration of Miao totems in morphological characteristics. In aesthetic culture of life reproduction of Miao nationality, the fish is deemed as the main reproduction signal due to lots of roes. Besides, in the mind of Miao people, they consider fish can become the dragon, while the dragon can also become fish. The two can be integrated into one. So, there is compound-type fish-dragon pattern as totemism. Such is applied to eulogize life reproduction in quantity in Miao embroidery.

Common compound-type totems include: fish-dragon, snake-dragon, silkworm-dragon, shrimp-dragon, leaf-dragon, flower-dragon, flying dragon, lion-dragon, and dual-dragon, etc. The features of these combined totems are as follows: there is no beard in the head part, and the other parts are consistent with the expression forms of traditional dragon head; the body of dragon is varied according to the morphological characteristics of specific animals. Miao people give dragon fine wishes - they hope their ancestor is the embodiment of dragon. It is the carrier of fine wishes. Based on this, they hope their descendants can be protected. Dragon totem - the ideal crystal in the idea of Miao people, reflects Miao people are eager to restrict stifling status of the realistic life.

(2)Religion and witchery culture make "dragon" become a symbol of exorcising evil spirits and praying for good luck. Plekhanov pointed out in On Art that, "The art of any nation is decided by the psychology". The dragon totem art of Miao nationality in religion and witchery culture serves for propagating religious thought, like other religious art. Totemism of Miao nationality also psychologically reflects their religion and witchery culture. Miao people regard dragon totem as supremacy - first ancestor of nationality or family ancestor, patron saint or symbol. They hope to gain propitious expectation and faith by dragon totem. It can be seen from the dragon totemism activity of Miao nationality and comparative analysis of dragon totem that, dragon totems have diversified and rich shapes.

Joyful and kind expression. The Miao nationality in the west of Hunan and the southeast of 
Guizhou Province has religious activities such as setting up dragon post, lifting dragon flag or establishing dragon shrine. Since the religious activities aim to pray and seek spiritual comfort, modeling features of dragon totem present kind and joyful expression. Dragon shrine is typical. The modeling materials of dragon totem are simple, including plant stem with mud, ear of rice and paper, etc. It is made through stacking small hillock, cutting and pasting paper, and drawing. The handling method is simple and plain. The features of eyes, mouth and main part of head are highlighted, and the expression is intensified. In particular, the eye is sharp, but not cruel. The beard and the body of dragon as well as other parts adopt image-oriented technique for modeling, or they are even omitted. Although this is against traditional form of dragon, the propitious meaning is not lost. Besides, the color is warm and full of decoration meaning, so the image is very jubilant.

Threatening and horrible expression. Various faith customs such as witchcraft and animism cater to people's faith psychology. The totem of Miao nationality as local natural god and humanistic god and religious god contains strong superstition color. Miao people conclude the phenomena which do not exist in real life and have not been known in nature to god's actions. Dragon totem is reflected especially obviously in this psychological appeal. All images collected with dragon are deemed as the embodiment of "dragon", and people taboo some phenomena of "dragon's actions".

(3)Nature worship, graft totem. Human beings linked themselves with animals and plants through imagination and made blood relationship happen. Indeed, folk customs and spirit of ethnic group dominate connotation and meaning of dragon totem of Miao nationality and relevant patterns. Chin You is the ancestor of Miao nationality, while dragon is the opponent of Chi You. Thus, according to the legend, in The 12 Eggs of Gu Ge, "water dragon" is just one of the 12 eggs without the sovereign status. Based on such cultural background, "dragon" pattern could be seen in Miao costume. It can be seen from many patterns on silver ornament and costume that, the dragon has no mysterious feeling. Dragon pattern is even a symbol which can be "grafted" with all kinds of animals.

\section{Fantasy property of modeling and visual weirdness}

In the living material carrier of Miao people in Qiandongnan, dragon totem embodies in costume embroidery, silver ornament, wax printing, weaving and other art forms. Miao people carry out role design and modeling for dragon totem by these material carriers, and embody the special implication to form excellent craft art. Miao people reflect many legends on various material carriers in the form of pattern and create them for appreciation. But the dragon totem modeling reflected on the material carriers gets rid of materialistic worldly idea. It does not aim to reflect concrete intention or describe the objective object, but aims to embody mental feelings and wish expression. It expresses inner passion and forms image fantasy and visual dimension.

(1)The adjustment of modeling dimension vision makes the image generate fantastic interest and charm. The dragon totem image of Miao nationality breaks through visual constancy and space as well as 3D mental formulary through dimension vision and makes dragon totem image generate mental fantastic interest and charm. From the perspective of modeling art, any object forms 3D and space relation by 3 aspects and 3 dimensions. Due to the reason for materials, dragon totem modeling of Miao nationality adopts image handling in the form through dimension handling and individual typical partial shape with almost artists' design idea and creation means. In this way, dragon totem modeling surpasses visual space limitation and visual mental constancy, and generates fantastic interest and charm. For example, the head is totally lateral, seeing from the face and mouth, but the two eyes are provided. This brings the visual mental effect of both front and side. For some patterns, the eyes, nose and the horn are the front image, but the mouth is standard front form. Besides, the head, body, foot and tail of many dragon totem patterns are not in the unified trend and the same orientation. Even so, "god" imagination and atmosphere of dragon totem express the distance between "god" and reality and fantastic imagination and creativity in the mind of Miao nationality.

(2)Intangible and tangible modeling makes the image form fantastic interest and charm. "Intangible" does not means "shape" is not important, but refers to the importance of "god". "Tangible" refers to modeling rule. Although the dragon totem modeling of Qiandongnan pursues natural beauty of dragon's form, original chaotic thinking feature and imagery mental trait of folk 
customs decide dragon totem modeling has the inherent humanistic feeling and humanistic connotation, shows the perfect mental image of "heart", "shape", "meaning" and "god" and presents weird complex, interest and charm in production and life of Miao people. Such weird art characteristic does not reflect ugliness and beauty as well as good and evil, but appears through the rare, strange and surreal abnormal situation. It is an unusual and approximately whacky art form. The folk art form of this miraculous nation introduces aesthetic characteristics, evolution form and aesthetic form of weird art as well as the similarities and differences with other art forms, interprets Miao people's weird art thinking idea and full art creation passion which derive from religion, folk customs, production and life.

In one word, "dragon" totem art of Miao nationality gathers their spiritual demand and the psychology of worshiping dragon. Folk custom and idea of ethnic group are integrated in the story about "dragon", which gives dragon totem more human factors. Similarly, these secular ideas extensively reflect social life of Miao people so that the modeling of dragon totem has strong ethnic characteristics and shows chaos characteristic of original thinking mode. Therefore, dragon totem not just very successfully gives play to its functions in religion, witchery culture and totemism and fully shows inheritance, but also makes people appreciate "local" aesthetic taste of Miao people.

\section{Acknowledgement}

This research was financially supported by 2013 National Philosophy and Social Science Foundation of Art Project "Wuxi drainage area national folk art inheritance system and technology division cataloging and research" (13BG063).

\section{References}

[1] Wang Liu, On Art Features, Beijing: Culture and Art Publishing House, 1986: 128.

[2] Zhu Xiaoming, Exploration of Intrinsic Value of Silver Ornament of Miao Nationality from Perspective of Structure Art, master's thesis of Tianjin Polytechnic University, 2007.

[3] Dan Na, Philosophy of Art, Hefei: Anhui Literature and Art Publishing House, 1991: 5.

[4] Xu Jianguo, Spirit and Emotion - Cultural Connotation of Chinese and Western Sculpture, Beijing: Commercial Press, 2003: 22.

[5] (US) Rudolph Arnheim, Visual Thinking, Chengdu: Sichuan Renmin Press, 2005: 146. 